\title{
A Day in the Life of an Early Childhood Teacher: Identifying the Confronting Issues and Challenges That Arise
}

\author{
Sarah Ohi \\ School of Education, Faculty of Arts \& Education, Deakin University, Melbourne, Australia \\ Email: sarah.ohi@deakin.edu.au
}

Received 22 April 2014; revised 17 May 2014; accepted 8 June 2014

Copyright (C) 2014 by author and Scientific Research Publishing Inc.

This work is licensed under the Creative Commons Attribution International License (CC BY). http://creativecommons.org/licenses/by/4.0/

\section{(c) (i) Open Access}

\begin{abstract}
Recent emphasis upon Early Childhood as an educational priority for the Australian Government has resulted in increases in funding, government initiatives, course providers and the introduction of new policies to the sector in order to improve the quality of early childhood education. The study reported here investigated the "reality" of what it means to be an Early Childhood Teacher within this changing context and identified the roles and responsibilities and the associated challenges. A case study involving observation and interviews with five Bachelor qualified Teachers from varied early childhood settings was undertaken in order to gain knowledge about their experiences and perspectives on their work. The data were analyzed using a grounded theory approach involving the identification of key themes and issues about the nature of teachers' work. The findings revealed that in their everyday practice teachers played a complex array of roles that required them to contribute far more than just their teaching skills and knowledge. They were expected to concurrently enact the roles of educator, leader, advocate, communicator, counsellor and administrator whilst juggling everyday challenges including a "lack of time", the need for "further support and more resources" and "building successful partnerships with parents".
\end{abstract}

\section{Keywords}

Teaching, Teachers, Teachers' Roles, Early Years, Early Childhood, De-Professionalization, Professional Identity

\section{Introduction}

The emphasis upon improving the quality of Early Childhood Education is not unique to Australia as it is 
growing in prevalence on an international scale. Metaphorically speaking, it is as though the winds of change have blown away the thick, grey storm clouds that once loomed over and shrouded the Early Childhood sector from view. Now with freshly opened eyes, governments on a global scale are able to see more clearly and consider a new perspective and to strive to nurture speedy growth in an enduring steadily growing plant; the Early Childhood sector.

Recent emphasis upon Early Childhood as an education priority area for the Australian Government has brought a welcome influx of funding to the sector with the aim of improving the quality of education in this sector. Many of these funds have been directed towards introducing a number of initiatives, strategies and policies aimed at supporting the expansion of existing Early Childhood Teacher Education programs. The funds are also being used to provide professional learning to support the implementation of the newly introduced requirements with the main aim being to improve the quality of Early Childhood education for children in Australia.

Since the introduction of this first wave of initiatives in 2007, a number of significant changes have resulted and impacted enormously upon the Early Childhood field in Australia. The promise of providing universal access to Kindergarten programs for all four-year-old children was accompanied by the requirement that the sessions be increased to 15 hours per week and that they be taught by a four-year degree qualified teachers (Spreadbury, 2008; Kronemann, 2008). Unfortunately this increase in hours has resulted in the widespread closure of many three-year old kindergarten programs, due to a complex mix of factors. Many of these centres lacked the capacity to sufficiently timetable the use of their buildings to accommodate the increased program hours due to limited space, resources and a lack of funding to provide the correct ratios of qualified staff.

Explanatory Note: In Victoria, Australia the word "Kindergarten" is used to refer to the final year of early childhood education that precedes the first year of formal primary school education. The teachers who conduct these programs are often called Kindergarten Teachers or Early Childhood Educators. Within this article these teachers will be referred to as Early Childhood Teachers as it is felt that this title adds clarity and will better cater for the international readership of this journal.

The government's imperative that Kindergarten programs in all early childhood contexts (including childcare) be led by four-year degree qualified Early Childhood Teachers by 2014 has had a huge impact upon the field. Prior to this mandate the majority of staff working in the field of early childhood had 2-year diplomas. Millions of dollars have been provided by the Australian Government to remove fees for Diplomas, to fund additional places in Universities and to reduce the study debts of Early Childhood Teachers. As a result of these movements, Australia finds itself in an unprecedented position where the need has been created for Teacher Education courses to undergo sudden expansion to cater for the influx of Early Childhood Educators that want to undertake or upgrade their qualifications. Considering the large amount of money being invested in expanding and supposedly "up-skilling” the Early Childhood workforce, it is timely that research be conducted about this profession so that we are clear about what this job of the Early Childhood Educator entails in practice.

In 2009, the Federal Government released Australia's national Early Childhood Policy documents for children aged 0 - 5 (Commonwealth of Australia, 2009) and shortly thereafter, in that same year, the State of Victoria launched its own policy documents for children aged 0 - 8 years. The purpose of these framework policies was to provide Early Childhood Teachers with a unified approach to planning and programming by which to guide the development of quality teaching programs. The introduction of these policies has meant that Early Childhood teachers have been expected to make changes to their planning and programming processes by implementing the policies in their centres.

\section{Literature Review: Teacher's Professional Practice}

The present study sought to investigate teachers' perceptions of their professional identities in this context of massive change to answer the posed research questions; What is the nature of their work? How do they perceive their roles? What are the main issues and challenges confronting them in their day-to-day work?

Although now a strong priority area for the Australian government, in many respects Early Childhood has in the past, arguably been a marginalized area of focus within the field of education (Fenech, Waniganayake, \& Fleet, 2009; Bown \& Sumison, 2007); undervalued as a profession in comparison to Primary, Secondary and Higher Education sectors. It seems likely then that changes in policy and the introduction of new policy frameworks, will bring with them, new, unforeseen challenges (Kronemann, 2008) as the governments seeks to further "professionalize" them. 
There is a rich history of research into “Teacher's Work” in educational settings (Goodson, 2003; Delandshere \& Petrosky, 2001; Clandinin \& Connelly, 1995) and there is a plethora of, and an ongoing need for, further that researches Teacher Education (Evans \& Pauling, 2010; Cochran-Smith \& Zeichner, 2005; Sikula, 1996; Valli, 1992) with most of this research focusing upon those that work in the Primary, Secondary and Tertiary sectors of the field of education. The body of research focusing solely upon teacher's work in Early Childhood Education however, is much more limited. Research into the nature of the "work" of Early Childhood Educators is an under researched area in need of further contribution (Dalli \& Urban, 2013). The current surge in the number of investigations into Early Childhood Teaching practice and the work of teachers in this field is a response to this need.

Ohi $(2007,2008)$ found that the introduction of literacy policies in the primary school sector in Victoria, Australia, served to de-professionalize even highly experienced teachers’ practice by positioning them as disempowered "implementers" of policy. The study found that teachers were striving to achieve accountability measures passed down through the political conduit. Similar findings are now echoed in the Early Childhood sector. Urban (2008) has already conceptualized the provision of policy framework documents to guide teachers in improving their programs as an example of the technicization of Early Childhood teaching. In similar vein, a growing number of findings resemble many of the challenges identified in other education sectors, including the de-professionalization of teachers, lack of empowerment experienced by early childhood teachers and reports of constrained practice (Overton, 2009; Bown \& Sumison, 2007). There has been some research into the way in which Early Childhood Educators experience organizational change (Burgess \& Fleet, 2009) and go about their work in response to reform agendas (Comber \& Nixon, 2009). However, more research that is concerned with a focus upon the perspectives of Early Childhood teachers (Comber \& Nixon, 2009) and the construction of their professional identities (Whitehead, 2008) is needed, including in the context of Victoria, Australia.

There is growing consensus that there is a lack of research to date, focusing upon Early Childhood Teachers' own views of their profession (Lloyd \& Hallet, 2010; Adams, 2008; Jones, 2008; Woodrow, 2007) and the study reported here contributes to addressing this need to identify Early Years teachers' views of their own Professional Identity. Gaining a better understanding of current practice and issues arising in the profession contribute a valuable piece quality improvement puzzle in this area.

\section{Method}

This study utilized a case study approach (Stake, 2010), in order to gather data about the varied experiences of individual Kindergarten teachers in the South-Eastern region of Victoria. Case studies are valued for their ability to capture a snap-shot of the realities of people's lived experiences and to identify and understand the uniqueness and complexities of the case at hand (Stake, 1995). There is strong support for the use of case study as a methodological tool for descriptive, explanatory and exploratory research purposes (Yin, 2012). Somekhe \& Lewin (2005) describe the complexity of the case study researcher's role as trying to "engage with and report the complexity of social activity in order to represent the meanings that individual social actors bring to those settings and manufacture them” (p. 33).

Observation and interviewing methods were employed to enable the collection of rich, in-depth data (RobertHolmes, 2011). The strength of this approach is its capacity to identify information about participants' views and the understanding that underpins their practice (Mukherji \& Albon, 2010; Somekhe \& Lewin, 2005). Furthermore, semi-structured interviews were conducted for their ability as a tool to illuminate complex issues, which may otherwise go unnoticed (Mukherji \& Albon, 2010). The semi-structured nature of the interviews provided flexibility, enabling the interview to be tailored according to the participant's interests and responses (MacNaughton, 2001).

\subsection{Recruitment of Participants}

This qualitative case study involved investigation into the everyday work settings of five teachers of 4-year-old Kindergarten. The participating Early Childhood Educators were found via the use of "Snowball Sampling" with the researcher "tracing" referrals provided from other professionals in the field in order to select participants known to meet the requirements of this research; that is, "experienced” Early Childhood Educators who are working in Childcare, Kindergarten and Early Learning Centre settings in the Eastern region of Victoria. Although each teacher worked largely with 4-year-old Pre-school children they were from varied Early Childhood 
settings. The region was scoured for a participant from one of each of the following; a Government funded Kindergarten, a privately owned Church Kindergarten, an Early Learning Centre within a private school context, a Long Day Care Centre and a Community based/Council owned Kindergarten.

The management leaders of each organization were approached via telephone and approval sought to contact potential participants via a mailed/emailed letter of invitation. If interest was expressed the researcher provided the Plain Language Statement and Consent Forms to the potential participant via e-mail, mail or delivery for their consideration until five participants were found. The Early Childhood Educators were asked to allow the author to observe them for an entire working day as they engaged with the everyday tasks and responsibilities that their job required. The researcher's role was to understand and identify the types of tasks and responsibilities that the teachers fulfilled, in order to gain a better understanding of occupations in the Early Childhood field and to understand and appreciate the array of important things that they did as a part of their employment.

In the spirit of ethnographic inquiry, where "the researcher strives to see things from the perspective of the participants” (Crotty, 1998: p. 7), semi-structured interviews were used with non-directive, open ended forms of questioning. During their lunch break the teachers volunteered to engage one on one, 30 minute semi-structured interviews during which they were asked a series of questions in relation to their views about their professional identity, the role of an Early Childhood Educator and what it entails and also the main challenging issues that they were confronted with.

\subsection{Analysis of the Data}

The teacher interviews were audio-taped, transcribed using pseudonyms and analysed using a grounded theory approach in which the underlying themes and categories emerge from the data being studied (Strauss \& Corbin, 1998; Glaser \& Strauss, 1967). As Connell (1985) points out, interviews are a valuable approach for investigating and analysing teachers' views, "Teachers' views of their work can be analysed in terms of the concepts they use, the knowledge they have, their pictures of teaching and views of education generally” (Connell, 1985: p. 182).

The information collected about the participants' everyday work and their views on their roles and responsibilities were manually coded into themes. The themes were derived from a combination of the identification of recurring themes and patterns that were apparent in the transcripts of the interview data by comparing and contrasting experiences and those that were found illuminated in light of previous research.

\section{Findings and Discussion}

Two main findings were identified by this study, firstly the multi-faceted nature of the work of the Early Childhood teacher and secondly, the ongoing daily challenges that arise. This discussion begins with a focus upon the first finding, Teachers' Perceptions of their roles in their workplace, followed by a discussion highlighting the key, everyday challenges experienced.Nb. Pseudonyms have been used to maintain the confidentiality of participants. The years of teaching experience of the teachers are placed in brackets with the pseudonym).

\subsection{Teachers' Perceptions of Their Roles}

The first point to note is that all of the participants in this study identified their work as an Early Childhood teacher as involving juggling a complex mix of roles. When asked to describe the nature of their work and what it entailed all participants commented upon the multi-faceted nature of their work.

... a very challenging, diverse role and it covers everything, really, doesn't it? (Julie, 30 yrs).

...encompasses a lot of areas...Yes, it's such a huge role (Allison, 10 yrs).

Lauren's description was more detailed, providing a comprehensive list,

Basically I feel like some days I'm a Psychiatrist, a Psychologist, a Counselor, a Doctor, a Nurse... everything rolled into one, on top of that... an Accountant. There are so many different facets of the work. I do administration duties, I do all the program planning, the development with the children. I liaise with outside Educators and outside people... there is a lot of different avenues and a lot of different, things we've got to do in a day (Lauren, 8 yrs).

On the whole, the teachers viewed themselves as playing a number of essential roles for the children and parents in their Kindergarten community. This experiencing of feeling inundated and pressured by the demands 
made upon them is congruent to the teachers' views shared in Bown \& Sumison's (2007) study who through vivid, visual representation revealed their experience of feeling bound to an office chair and even sacrificing themselves, only to be to pecked apart one piece at a time by birds.

A few roles in particular were common to the experiences of the participants in this study and these were “Teachers as Educators”, “Teachers as Pastoral Care Providers”, “Teachers as Communicators”, “Teachers as Leaders" and "Teachers as Advocates". Each category emerged directly from the common words shared in the interviews. Each of these will now be discussed in turn.

\subsubsection{Teachers as Educators}

Not surprisingly, when asked how they perceived their role, the main role that each of the five teachers expressed as most important was that of the Educator;

Obviously educating young children (Allison, $10 \mathrm{yrs}$ ).

As an Educator; an Educator for parents... an Educator for the children (Danielle, 12 yrs).

I encourage children to participate and embrace the program, planning, programming, evaluations, scaffold the children's learning... parents, know the families and the children (Julie, 30 yrs).

We're their Facilitator, we're only here to facilitate them to become the person they would like to become and to develop on what they've already developed. We're here to facilitate and help them develop and grow (Lauren, 8 years exp).

Interestingly, some of these comments are clearly grounded in educational theory with connections made with Vygotskian views of "scaffolding” and "facilitating” children's learning (Jacobs, 2001) and also upon the importance of drawing upon children's funds of knowledge (Moll, Amanti, Neff, \& Gonzalez, 1992) by getting to know their families.

\subsubsection{Teachers as Communicators}

The teachers described their need to be able to communicate effectively with an array of people, from various positions and a range of organisations. Allison's comments below effectively encapsulate this,

Being a good...Communicator. (It) involves trying to get your point across in a lot of different ways because you've got quite a large target audience. So it's not only communicating with the children, it's the parents, it's committees... We've got our other Directors, it's other Staff members, it's other Early Childhood Professionals. So that sort of role is quite important (Allison, $10 \mathrm{yrs}$ ).

Given the multi-faceted nature of their teaching role it is no surprise that teachers would need to be effective communicators. The importance of their role as communicators however, should not be discounted, as it essential in enabling them to get things done and to make things happen.

\subsubsection{Teachers as Leaders}

Another role, common to the Early Childhood teachers' perceptions of their identity was that of Leader. The teachers understood themselves as Educational leaders responsible for the programming and pedagogy and also as leaders of the Early Childhood setting who conducted meetings, addressed parents, staff, council, committees, networks and schools.

As Deputy Head, yes I'm often needed to step out of the room and show people around the centre or to speak to parents... I do find that the role of being Deputy Head just adds different things. Other staff members will come to me to be able to discuss things too. Also I'm in charge of Professional Development (Julie, 30 yrs).

I think as a Leader. The parents look to you as a Leader and as being a Specialist in Early Childhood development and Early Childhood Education. Certainly the staff that you work with look to you as a leader too; that's your Assistant and any Integration Assistants that you might have and here we've also got 3-Year Old Staff. So I guess its like the Captain of the Ship, You've got the ship underneath you and all these people are looking towards you (Danielle, 12 yrs).

\subsubsection{Teachers as Advocates}

In describing their roles as Early Childhood Teachers each participant engaged in discussion of their role as advocates for the children that they worked with. Kelly described her role in supporting children identified as "another voice",

Some children don't have the "safeness" of home so, the Department feels as though they're better off here 
five days a week then at home during the day (Kelly, 3 yrs).

Lauren and Danielle indirectly discussed their roles as advocates whilst discussing other information, however, Allison and Julie both explicitly used the used term advocate in describing their professional roles, with Julie stating that teachers are advocated for the field of early childhood.

First and foremost you're an Advocate for the children...you're there for the children no matter what and they come as number one (Allison, 10 yrs).

Knowledge is really, really important...People do look to us and we need to know why we're doing things and to be able to express and back up why we're doing it too. To not only the parents, but anyone that might be interested in the program. To be an advocate of early childhood (Julie, 30 yrs).

\subsubsection{Teachers as Pastoral Care Providers}

It is interesting to note that all teachers discussed the importance and need to work with parents, however the "pastoral care" aspect of this dimension of their work came through very strongly in the interviews of two of the teachers as evidenced in the following two excerpts. The pastoral care role was reported in relation to supporting parents who had personal crises and supporting parents through the journey of identifying if their child may have additional needs or a disability of some sort.

You often get parents crying because they're concerned about their child. Worried about certain issues so we always have parent Fact sheets for them. Information evenings etc. to be able to soothe them because you know it must be quite difficult. ...They don't know what to do sometimes. They get very confused and very worried about their child. So we try and help them through that, through the knowledge that we have, as well as external knowledge and information (Lauren, 8 yrs).

Researcher: Do you feel that you were well prepared by your Course, to under-take all of the roles that you have described?

No, particularly my first course, my Diploma. I wasn't prepared for the challenges. Age and experience have prepared me more. We did a lot of relevant subjects of course, you know like Maths, Dance and Drama and things like that. We did do a subject on psychology, but I think we needed, more assistance on, 'who' is out there. Who can help us? How can we contact the Department? What is an occupational therapist? You know, as a 21 yr old coming out of university - I had no idea (Lauren, 8 yrs).

Allison described similar feelings of uneasiness when adopting the role of Pastoral Care Provider,

The pastoral care side of it, that can be really quite draining...to be honest, that can be a really big challenge because I'm not trained in that area. I'm a very empathetic person and I want to help as much as I can and you end up taking on a lot of their woes and well, you know you can't help but I can't separate that part.

You still maintain that professional attitude and everything, but it can still be quite hard to separate that. When you see a dad walk and you know he's just cheated on his wife and the mum's been, you know, she's going through depression and all sorts of....(uncomfortable laugh)... and you go..."oh my gosh"....(uncomfortable laugh)..."Hi"....

So that's been a really tricky thing. That, I think, is lacking again in the Training and in the understanding as well. You know, you don't realize that you're going to come out to that. And I'm sure it... if that's part of my personality, that parents feel that they can talk to me in that way (Allison, $10 \mathrm{yrs).}$

As expressed in the above excerpts the teachers felt ill-prepared by their training in playing the role of Pastoral Carer, yet it was a role that they were compelled to adopt. The pastoral role was viewed as highly challenging with teachers wanting further support and knowledge to assist them in supporting parents at their centres.

\subsubsection{Teachers as Administrators}

Danielle's description of her role as an Administrator covers all areas mentioned by the other Early Childhood teachers and is an exemplar of the extent of the administrative paperwork expected to be completed by Early Childhood teachers' in Australia,

It's everything to do with the children and their parents that come into the program. So right from the beginning, enrolling them and dealing with all the paper work that goes with enrolment. Chasing parents to make sure, because they always forget bits, so making sure that all the paperwork is complete. Then there's the programming side of it, the paperwork that's involved with programming. There is the actual working with the children, educating them, playing with them, teaching them things. There's evaluations, both of programs and 
the children, observations of children that need to be done.

Then in addition to that, there's satisfying the legal requirements for Children's Service, for the Department of Education. The Council has a lot of requirements that we need to complete. They insist that you do evacuations every term and there's paperwork to follow that, to prove that you've done it. But children, if you've got children with additional needs, you've got meetings, you've got reports to write and funding applications. Funding applications, you know, minor capital grants to write and those sorts of things.

What else do I do? There's heaps. I liaise with schools. There's been all the Transition reports and um.. network meetings with other teachers, staff meetings with Council, interviews with parents (Danielle, 12 yrs).

It is clear from these results that the early childhood teacher's role is complex and multi-faceted. An overview of these findings is presented in Table 1.

\subsection{Key Issues and Challenges Confronting Early Childhood Teachers Daily}

During the 30-minute interviews all teachers were asked to identify the three most challenging issues associated with their work. The issues were identified as "insufficient time", a "lack of resources" and also "working with parents" and these are discussed below.

\subsubsection{Lack of Time}

Four of the five teachers interviewed explicitly identified "lack of time" as a major issue that they confronted daily. The fifth teacher felt that she lacked the time to complete program planning and organizational paperwork. In this manner all teachers believed that they were short of allocated time to fulfil the expectations made of them.

Time. Time, time, time, time management...I'll have in my diary a list of things that I plan to achieve....and I'll go home at the end of the day and none of its done because things happen. You know... a delivery of stuff that's got to be unpacked... an order that needs to be done... a family will need to have a meeting with you...Just keeping up with the paperwork and keeping up with observations and programming is a challenge (Danielle, 12 yrs).

Time is an issue...As always, there's never enough time to do anything and you know, you always want to do better and more exciting things, so time plays on that one (Allison, 10 yrs).

I think we need more time because in our field so many things need to be done and you can't often do them with the children. There is our documentation, our reports... we can do them, but to follow them up? Program planning, setting up activities, researching activities, reading articles, planning for activities. You really do need to plan because if you don't, the children are disengaged, so planning is an important part it just doesn't happen and so I think time is another challenging thing (Julie, 30 yrs).

Lauren reported finding the recently introduced government Transition to School Statement Reports extremely taxing on her time,

Table 1. Teachers' perceptions of their roles.

The Teacher's Role Description

Teachers as Educators

Teachers as Communicators

Teachers as Leaders

Teachers as Pastoral Care Providers

Teachers as Administrators

Teachers as Advocates
Educators are actively involved in educating children and sharing information with parents and staff about children's learning and development.

Educators need to communicate well with children, the parents, committees, the Director, other Staff members, other Educators, the Council and the community.

Educators are educational leaders responsible for the planning, programming and teaching. They are also leaders of the Early Childhood setting who conducted meetings, address parents, staff, council, committees, networks and schools.

Some parents find the Educators very supportive and confide in them about their problems. The Educator endeavours to direct them to community support services that can provide them with assistance with these other aspects of their lives.

Educators are administrators who organize enrolment procedures and paperwork, educational program planning, observing, recording and evaluating children’s learning ensuring legal requirements are adhered to, organizing evacuations, excursions, special visitors, special events, paperwork involved in supporting children with additional needs, reports to write and funding applications, organizing transition programs with schools and writing transition reports and more!

Educators viewed themselves as advocates for the children that they worked with, giving them a voice, providing a safe and nurturing learning environment. 
It's very time consuming. It took me... I wouldn't be able to calculate how many hours, but it did take me about 3 weeks to complete and I was working often. So it really is time consuming...it would be fantastic if your environment gave you extra time to do it, but mine didn't, but that's my environment. There's not much I can do about it, so I did it in my own time (Lauren, 8 yrs).

\subsubsection{Insufficient Resources}

For a couple of teachers in particular (one from the Long Day Childcare and the other from an independent funded Early Childhood program), a main issue impacting upon the quality of their program was the lack of sufficient resources.

This sounds bad, but it's a poorer centre. So we don't have the experiences that I would have had if I took the job offered at a private school. So we don't have the Art equipment that a lot of Centres have. So everything's pretty basic. The resources... It's very challenging having to bring your own stuff in and having to pay for it (Kelly, 3 yrs).

Like yesterday (there was a minor flooding incident) working in a building that's seventy years old and its falling apart! (laughs). (Allison, 10 yrs).

\subsubsection{Working in Partnership with Parents}

Lauren reported enjoying working with parents, despite the intense Pastoral role that she adopted in supporting them. Allison, however, found working with parents in a Pastoral role highly draining (as previously mentioned). The remaining three Early Childhood Teachers, however, found it challenging to work in partnership with parents as illustrated in the excerpts below.

Parent Education....Management of young children, behavior and discipline and those sorts of things...I think these days they (parents) get much less Maternal and Child Health support. So I think that, that has probably taken away some of the education as well, of young parents (Danielle, $12 \mathrm{yrs}$ ).

They (the parents) want your help but they expect us to do it-like fix it "here". But it's "two-way". They need to help us to help. You know, we need their help and they need our help so we need to work together (Kelly, 3 yrs).

It's a good issue; to embrace parents in the program and to include them in the program and for them to be able to feel comfortable and want to participate (Julie, $30 \mathrm{yrs}$ ).

Interestingly, Overton's (2009) study of Tasmanian school teachers identified the issue of teachers experiencing disempowerment through devaluing and a lack of appreciation, the lack of provision of resources and funding and the lack of direct or indirect forms of support from the system and senior staff. The findings from this study found however, that early childhood teachers are experiencing disempowerment through the above mentioned daily issues and challenges of having a lack of time, needing further support and more resources and strategies as to how to build successful partnerships with parents.

\subsection{The Most Enjoyable Aspects of Early Childhood Teaching}

Each of the five Early Childhood teachers were adamant that working with the children was the most enjoyable and rewarding aspect of their work and interestingly, three of them also mentioned developing positive relationships parents as an enjoyable part of their work, despite that also being a daily challenge.

Working with the children. Just listening to them, listening to what they say. Just watching them develop and grow. I mean this morning it was nice to see them playing as a group which they haven't done that before. I guess working with the families and parents is enjoyable as well (Danielle $12 \mathrm{yrs}$ ).

One of the things is that every day is different and it's very spontaneous...You do plan and you anticipate, but everyday is very, very different. And I think it's wonderful to be able to have that flexibility to be able to engage in spontaneous moments. The other one, is the joy of watching the children grow and develop and it's something at this stage of the year (the end) you really get a lot of satisfaction and joy out of seeing how far they've come and where they are going. I think another one is building the relationships with parents and the families throughout the year and that does take a lot of work, but it gives you a lot of satisfaction of your work (Julie, 30 yrs).

In light of the previous discussion, it is clear that the participants in this study found their roles as EC teachers to be complex, taxing and highly challenging, yet this did not sway them from their ongoing professional 
commitment to working with young children and doing their best supporting them in their learning and growth.

\section{Conclusions: Implications of the Study}

This article has argued that Early Childhood teachers tend to feel disempowered in their everyday work environments when they are expected to adopt additional roles in the work place without the reception of extra support. Although Early Childhood teachers are qualified leaders in their field, nevertheless, their work practices are constrained by a number of everyday challenges that arise due to the ongoing expectation that they will fulfill a growing array of concurrent, complex roles in their workplace and this was found across all early childhood sites.

This case study of five Australian Early Childhood Teachers explored the teachers' professional identities and found that these particular teachers experienced their professional role as being complex and multifaceted. Essential to their role as Four-year-old Early Childhood teacher was the need to inter-changeably adopt the roles of “educator”, “pastoral care providers”, “communicators”, "leaders” and "advocates”, amongst other responsibilities, for the children, parents and communities at their workplace.

Two main issues confronted the Early Childhood Teachers on a daily basis. There was strong agreement that there was a lack of sufficient time to undertake all of the tasks and responsibilities compounded upon them in their roles as professionals. This problem reportedly, consequently impacted upon other issues, such as the quality of planning, programming, reporting and the amount of time spent with the children.

The second problematic issue raised was the difficulty in working with parents to create effective partnerships and this had various aspects to it. Apart from the pastoral care issue (discussed earlier), another area of difficulty was that some parents had impractical expectations that the Early Childhood Educator and staff were solely responsible for correcting children's behavioural problems. This problem was viewed as being related to a need for some parents to become more knowledgeable about child development and behavioural management. Interestingly, at the same time, building a positive rapport with parents was considered a positive aspect of the job, but working with the children and witnessing them learn and develop over time was viewed as the most rewarding aspect of being a Four-Year-Old Early Childhood teacher.

Additionally, another problematic issue was in relation to the need for up-to-date resources to ensure safety in the Early Childhood learning space and to support the development of more engaging learning experiences for the children. It could also be argued that further resourcing the teacher with extra time to attend to administrative and reporting tasks or the provision of support staff to assist with this would be beneficial.

The findings reported here are valuable in contributing to knowledge about "Teacher's Work" in Early Childhood settings and has implications and recommendations for EC teachers, their workplaces, teacher educators and government departments. Firstly it is important for the health and well-being of the EC teacher and the quality of the educational programs they develop for children, that all of these bodies understand and recognise the complexities that teachers are faced with in terms of the daily roles and responsibilities that they are expected to juggle. Are these realistic expectations? What can be done to improve these conditions?

In my view, it is the combined responsibility of the government, providers of Early Childhood Teacher Education and the EC workplace and the EC teachers to ensure that clarity is gained about the processes and protocols involved in supporting parents to seek professional support in areas of need, such as that highlighted in this study; in the form of pastoral care. Teachers need to know how to support/deal with parents who are experiencing challenging times. I envisage that this may take the form of receiving strategic training as to how to be empathetic towards parents, but at the same time be able to direct them to seek professional pastoral care or support. Clear boundaries need to be set in place in order to clearly define EC teacher's professional roles and responsibilities in order to support teachers in their profession and to protect them from being over-burdened and stressed.

Additionally, Early Childhood Education providers might consider supporting their teachers in further developing their skills in time management and organizational strategies. A recommendation is made to the Department of Early Childhood Education and Development to consider evaluating the amount of administrative paperwork required to be completed by Early Childhood Teachers in relation to the amount of time allocated for them to fulfil their work.

These findings are worthy of sharing with those working in the field of Early Childhood and employers of early childhood staff and also with the broader community in order to acknowledge the work that is done and to 
raise public awareness about the ways in which teachers strive, maintain and provide quality early Childhood Services. Sharing this knowledge is hoped to assist in improving people's understanding of the range of roles that are essentially adopted by Early Childhood teachers, however, evidently, more research is needed.

This study has found that Early Childhood teachers are inundated with problems associated with keeping up with the demands of increasing levels of accountability and find that they have a "lack of time", the need for "further support and more resources" and "the building of successful partnerships with parents". It is therefore important that Higher Education providers, Early Childhood employers and Government departments and policy makers become aware of the complexities and problematic nature of these realities and that they work productively to provide increased levels of support to Early Childhood teachers during their initial education and in an ongoing manner for those professionals in the workplace.

\section{Acknowledgements}

A special word of thanks is extended to Deakin University for funding this research via the Emerging Research Group grant. A word of thanks is also due to the voluntary teacher participants who generously gave their time and shared their stories. Finally, acknowledgement is made of those in positions of leadership in these workplaces and the Department of Education and Early Childhood Development for permitting this study to take place in these Early Years settings.

\section{References}

Adams, K. (2008). What's in a Name? Seeking Professional Status through Degree Studies within the Scottish Early Years Context. European Early Childhood Education Research Journal, 16, 196-209. http://dx.doi.org/10.1080/13502930802141626

Bown, K., \& Sumison, J. (2007). Voices from the Other Side of the Fence: Early Childhood Teachers' Experiences with Mandatory Regulatory Requirements. Contemporary Issues in Early Childhood, 8, 30-49. http://dx.doi.org/10.2304/ciec.2007.8.1.30

Burgess, J., \& Fleet, A. (2009). Frameworks for Change: Four Recurrent Themes for Quality in Early Childhood Curriculum Initiatives. Asia-Pacific Journal of Teacher Education, 37, 45-61. http://dx.doi.org/10.1080/13598660802534489

Clandinin, D., \& Connelly, M. (1995). Teachers’ Professional Knowledge Landscapes. New York: Teachers College Press.

Cochran-Smith, M., \& Zeichner, K. M. (2005). Studying Teacher Education: The Report of the AERA Panel on Research and Teacher Education (p. 816). Mahwah, NJ.

Comber, B., \& Nixon, H. (2009). Teachers’ Work and Pedagogy in an Era of Accountability. Discourse, 30, 333-345.

Commonwealth of Australia (2009). Belonging, Being, Becoming, the Early Years Learning Framework for Australia. Canberra: Australian Government Department of Education, Employment and Workplace Relations for the Council of Australian Governments.

Connell, R. W. (1985). Teachers’ Work. Sydney: George Allen \& Unwin.

Crotty, M. (1998). The Foundations of Social Research: Meaning and Perspective in the Research Process. London: SAGE Publications Inc.

Dalli, C., \& Urban, M. (2013). Professionalism in Early Childhood Education and Care. International Perspectives. Australia: Routledge.

Delandshere, G., \& Petrosky, A. (2001). Framing Teaching and Teachers? National Board English Language Arts Certification in the US. L1-Educational Studies in Language and Literature, 1 (pp. 115-133). Dordrecht: Kluwer Academic Publishers.

Evans, T., \& Pauling, B. (2010). The Future of Disctance Education. Reformed, scrapped or recycled. In M. Cleveland-Innes, \& D. Garrison (Eds.), An Introduction to Distance Education. Understanding Teaching and Learning in a New Era (pp. 198-223). New York: Routledge.

Fenech, M., Waniganayake, M., \& Fleet, A. (2009). More than a Shortage of Early Childhood Teachers: Looking beyond the Recruitment of University Qualified Teachers to Promote Quality Early Childhood Education and Care. Asia-Pacific Journal of Teacher Education, 37, 199-213. http://dx.doi.org/10.1080/13598660902804022

Glaser, B. G., \& Strauss, A. L. (1967) The Discovery of Grounded Theory: Strategies for Qualitative Research. New York: Aldine de Gruyter.

Goodson, I. (2010). Representing Teachers. In Qualitative Research Methods in Education (pp. 13-23). London: Sage Press.

Jacobs, G. (2001). Providing the Scaffold: A Model for Early Childhood/Primary Teacher Preparation. Early Childhood 
Education Journal, 29, 125-130. http://dx.doi.org/10.1023/A:1012581113983

Jones, C. (2008). Studying the Early Years Foundation Degree: Student Voices. In L. Miller, \& C. Cable (Eds.) Professionalism in the Early Years (pp. 109-118). London, Hodder \& Stoughton.

Kronemann, M. (2008). Keep Those Banners Ready: The Challenges of the New Early Childhood Agenda. Professional Voice, 6, 17-21.

Lloyd, E., \& Hallet, E. (2010). Professionalising the Early Childhood Workforce in England: Work in Progress or Missed Opportunity? Contemporary Issues in Early Childhood, 11, 75-88. http://dx.doi.org/10.2304/ciec.2010.11.1.75

MacNaughton, G. (2001). Doing Early Childhood Research: International Perspectives on Theory and Practice. Crows Nest: Allen \& Unwin.

Moll, L., Amanti, C., Neff, D., \& Gonzalez, N. (1992). Funds of Knowledge for Teaching: Using a Qualitative Approach to Connect Home and Classrooms. Qualitative Issues in Educational Research, 31, 132-141.

Mukherji, P., \& Albon, D. (2010). Research Methods in Early Childhood: An Introductory Guide. London: SAGE Publications Ltd.

Ohi, S. (2008), The Teacher's Role in the Research-Policy-Praxis Nexus. Australian Journal of Education, 52, 95-109.

Ohi, S. (2007). Teachers Professional Knowledge and the Teaching of Reading in the Early Years. Australian Journal of teacher Education, 32, 5.

Overton, J. (2009). Early Childhood Teachers in Contexts of Power: Empowerment and a Voice. Australasian Journal of Early Childhood, 34, 1-10.

Roberts-Holmes, G. (2011). Doing your Early Years Research Project. London: SAGE Publications Ltd.

Sikula, J. (1996). Handbook of Research on Teacher Education (2nd ed.), New York, Macmillan.

Somekhe, B., \& Lewin, C. (2005). Research Methods in the Social Sciences. London. London: SAGE Publications Inc.

Spreadbury, H. (2008). At Last: Pre-School Education a National Priority. Professional Magazine, 23, 32-34.

Stake, R. (1995) Case Researcher Roles, the Art of Case Study Research. Thousand Oaks, CA: Sage Publications.

Strauss, A., \& Corbin, J. (1998) Basics of Qualitative Research: Techniques and Procedures for Developing Grounded Theory (2nd ed.). Thousand Oaks, CA: Sage Publications.

Urban, M. (2008). Dealing with Uncertainty: Challenges and Possibilities for the Early Childhood Profession. European Early Childhood Education Research Journal, 16, 135-152. http://dx.doi.org/10.1080/13502930802141584

Valli, L. (1992). Reflective Teacher Education: Cases and Critiques. Albany, NY: State University of New York.

Whitehead, K. (2008). The Construction of Early Childhood Teachers' Professional Identities, Then and Now. Australian Journal of Early Childhood, 33, 34-41.

Woodrow, C. (2007). W(H)ither the Early Childhood Teacher: Tensions for Early Childhood Professional Identity between the Policy Landscape and the Politics of Teacher Regulation. Contemporary Issues in Early Childhood, 8, 233-243. http://dx.doi.org/10.2304/ciec.2007.8.3.233

Yin, R. (2012). Applications of Case Study Research. USA: SAGE Publications Inc. 
Scientific Research Publishing (SCIRP) is one of the largest Open Access journal publishers. It is currently publishing more than 200 open access, online, peer-reviewed journals covering a wide range of academic disciplines. SCIRP serves the worldwide academic communities and contributes to the progress and application of science with its publication.

Other selected journals from SCIRP are listed as below. Submit your manuscript to us via either submit@scirp.org or Online Submission Portal.
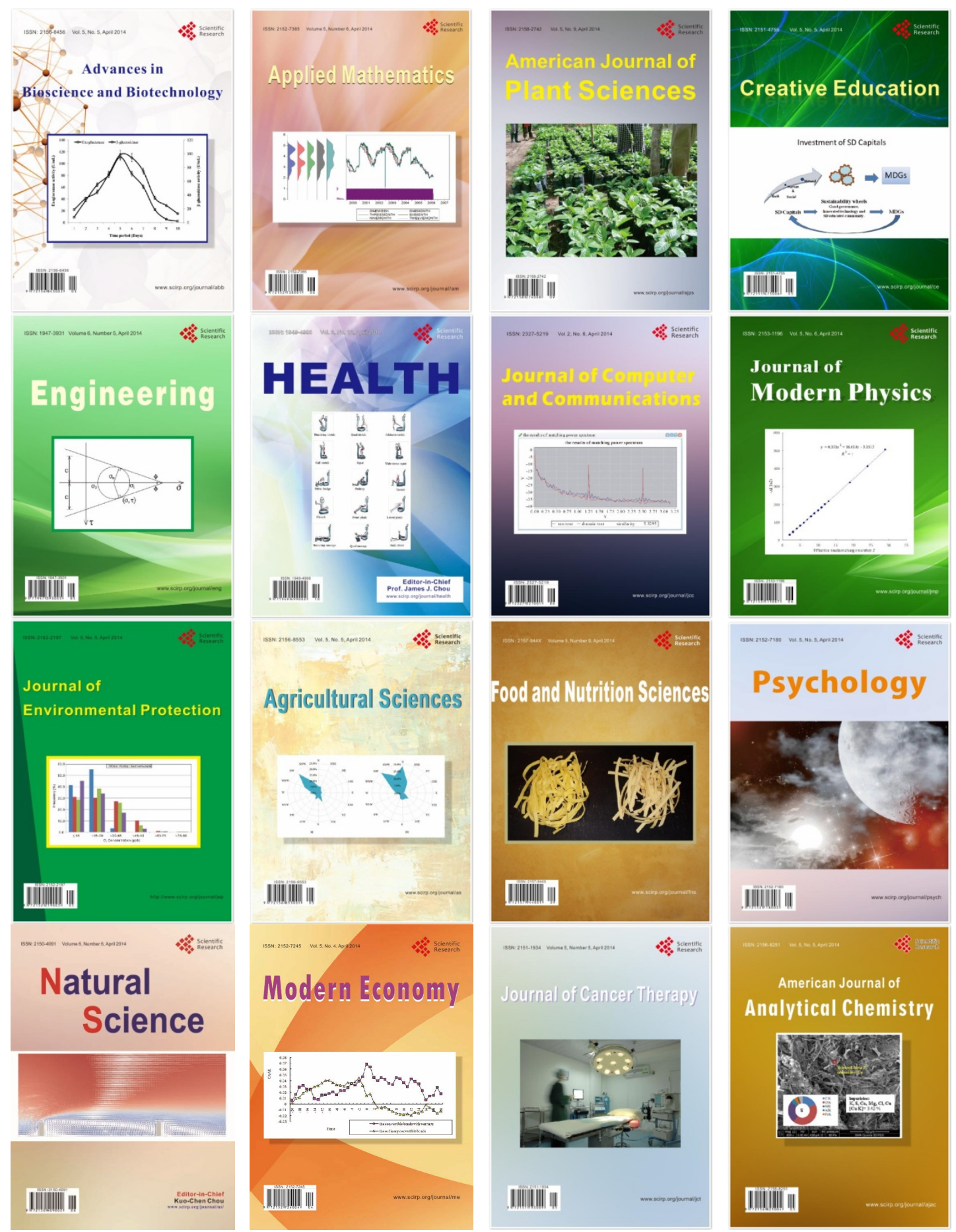